\title{
Shear strain localization in AA 2219-T8 aluminum alloy at high strain rates
}

\author{
G.M. Owolabi ${ }^{1 *}$, D.T. Bolling ${ }^{1}$, A.A. Tiamiyu ${ }^{2}$, R. Abu ${ }^{1,3}$, A.G. Odeshi ${ }^{1,2}$, H.A. Whitworth ${ }^{1}$ \\ ${ }^{1}$ Department of Mechanical Engineering, Howard University, Washington DC, USA \\ ${ }^{2}$ Department of Mechanical Engineering, University of Saskatchewan, Saskatoon, Canada \\ ${ }^{3}$ Department of Mechanical Engineering, University of Ibadan, Ibadan, Nigeria
}

\begin{abstract}
AA 2219 aluminum alloy is characterised by high temperature strength, good weldability and excellent suitability as choice material for several components in defense and aerospace structures. In this paper, the dynamic impact response of cylindrical specimens of AA 2219-T8 alloy was investigated using the split Hopkinson pressure bar while strain evolution during the dynamic deformation was monitored in-situ using digital image correlation (DIC) technique. The results of DIC analysis and microstructural evaluation of the impacted specimens indicated occurrence of heterogeneous deformation characterised by intense shear strain localisation. The strain localisation became noticeable after $80 \mu$ from the start of deformation. Both transformed and deformed shear bands developed in the specimens and they cracked along the transformed bands at high strain rates. Microstructural analysis of the as-received alloy suggested that it consists of two type of dispersed second phase particles: coarse particles which are 10-45 $\mu \mathrm{m}$ in size and fine precipitates of sizes less than $1 \mu \mathrm{m}$. Intense adiabatic heating and strain localization led to the dissolution of the coarse second phase particles inside the transformed bands while the fine second phase particles survived the heat. The dynamic mechanical response of the alloy and its tendency to form adiabatic shear bands are influenced by the length to diameter ratio of the cylindrical test specimens.
\end{abstract}

Key words: AA 2219 aluminum alloy, dynamic impact loading, digital image correlation, plastic deformation, adiabatic shear band

\section{Introduction}

Localised adiabatic heating often occurs during dynamic impact loading of metallic alloys leading to local thermal softening and intense strain localization along narrow bands called adiabatic shear bands (ASBs). The consequence is low fracture energy [1] leading to crack

*Corresponding author: E-mail: gbadebo.owolabi@howard.edu Tel. \#: 202-806-65941

(C) 2015. This manuscript version is made available under the Elsevier user license http://www.elsevier.com/open-access/userlicense/1.0/ 
initiation and propagation along the ASBs [2]. Armstrong and Zerilli [3]suggested that localized heating at dislocation pile-ups in BCC metal promotes formation of adiabatic shear bands at high strain rates. The microstructure of shear bands in metallic alloys can vary from elongated grains in deformed shear bands (DSBs) to ultrafine grains in transformed shear bands (TSBs). The ultrafine grains in transformed shear bands are proposed to form by dynamic recovery or dynamic recrystallization (DRX) [4], both of which are consequences of dislocation dynamics within the ASBs during formation. DRX in shear bands occur by rotation mechanism rather than by grain boundary migration that is typical of static recrystallization[5],[6]. Contrary to the popular opinion that thermal softening promotes strain localization and DRX in adiabatic shear bands, Osoviski et al. [7], [8] opined that DRX promoted by the stored energy of deformation contributes to strain softening leading to the formation of ASBs. They suggested that the role of thermal softening is negligible in materials that exhibit early DRX while thermal softening dominates in materials that exhibit late or no DRX [8].

Both deformed and transformed shear bands have been reported to develop in aluminum alloys during high strain-rate deformation[2], [9]. A minimum critical strain for formation of deformed and transformed bands is reported for AA $8090 \mathrm{Al}-\mathrm{Li}$ alloys, while the strain inside the ASBs and the global strain in the impacted specimen were determined to be 8.0 and 0.25 respectively [9]. The critical strain for occurrence of shear bands in metallic alloys depends on the strain rates, temperature and grain size [10]. The propensity of an aluminium alloy to form ASBs and fail at high strain rates is dependent on the initial temper condition[2], [11], [12]. Owolabi et al. [13] reported that ceramic particle reinforcement of AA 6061-T6 alloy affects its susceptibility to formation of ASBs. Shear bands can develop in some aluminium alloys under both quasi-static loading and high strain-rate compressive loading, although the intensity of strain localization is higher at high strain rates [14]. Shear strain localization acting as precursor to failure in aluminium alloys will continue to attract research interest in order to generate mechanical and microstructural data needed for an in-depth understanding of their behaviour under dynamic impact loading condition and for mitigation of impact failure.

AA 2219 is a high strength Al-Cu alloy with excellent weldability and it retains its good mechanical properties over a wide range of temperatures from cryogenic up to $250^{\circ} \mathrm{C}$ [15]. This 
makes it a candidate material for propellant storage tank in space vehicles. Surekhaet al. [16][18] identified galvanic coupling between coarse $\mathrm{Al}_{2} \mathrm{Cu}$ particles and the continuous $\alpha$-Al phase in its microstructure as a major setback to the use of this alloy in some applications. Surface treatment can be used to refine the structure and make this alloy resistant to galvanic corrosion [16]. Narasayya et al. [15] reported on the tensile behaviour of the alloy under different aging condition while Suenger et al. [19] also discussed the influenced of processing parameters on the alloy's hardness. Jha et al. [20] investigated the failure of AA 2219 aluminum alloy used in welded propellant tank for space vehicle and traced its fracture to occurrence of strain localization and formation of ASBs. Evidence of melting, underscoring the intensity of adiabatic heating, was also observed on the fracture surface of the tank. Since information on the dynamic mechanical response of this alloy in relation to shear strain localization is limited, it is imperative to investigate the various parameters that can influence shear strain localization in AA 2219 aluminum alloy at high strain rates. In the current study, the microstructural evolution accompanying shear strain localization in cylindrical specimens of AA 2219-T8 aluminium alloy is investigated. The effects of length to diameter (aspect) ratio of the test specimens on its dynamic mechanical response and susceptibility to strain localization and adiabatic shear failure are discussed.

\section{Materials and Methods}

The investigated AA 2219-T8 aluminum alloy was supplied by the NASA research center. Its nominal composition is presented in Table 1. The alloy can contain up to $6.8 \mathrm{wt} \% \mathrm{Cu}$ with minor additions of $\mathrm{Mn}, \mathrm{Ti}, \mathrm{V}$ and $\mathrm{Zr}$. Iron is an impurity that is commonly present in most aluminum alloys and its content in AA 2019 can be up to $0.3 \mathrm{wt}$.\%. The high copper content is responsible for the excellent weldability of this alloy [21]. Two groups of cylindrical test specimens having a diameter of $5 \mathrm{~mm}$ were machined and subjected to dynamic impact test. The specimens in the first group have the same length as the diameter $(L / D=1)$ while those in the second group are $4 \mathrm{~mm}$ long $(L / D=0.8)$ as shown in Fig. 1 . The impact test was conducted 
using the split Hopkinson pressure bar (Fig. 2). It is an ideal system for achieving uniform uniaxial compression of specimen at relatively constant strain rates in excess of $10^{3} \mathrm{~s}^{-1}$.

Excluding the necessary infrastructure to support the system, the split Hopkinson pressure bar consists mainly of three main bars; striker, incident and transmitter bars, which are made of Ti$6 \mathrm{Al}-4 \mathrm{~V}$ alloy. This alloy was chosen based on its high threshold for plastic deformation. The striker bar is fired using compressed nitrogen gas from a pressurized gas chamber. It strikes the incident bar generating an impact load that rapidly compresses the test specimen sandwiched between the incident and transmitter bars. The firing pressure of the strike bar was adjusted to produce strain rates ranging between 1000 and $6000 \mathrm{~s}^{-1}$ in the specimens. An elastic wave generated when the striker bar strikes the incident bar travels along the incident bar towards the specimen. A portion of the wave transmits through the specimen and to the transmitter bar while another fraction is reflected back through the incident bar. The incident, reflected and transmitted elastic waves are captured by strain gages attached to the bars. These were conditioned, amplified and recorded on a digital oscilloscope. The following equations were used in generating the stress $(\sigma)$, the strain $(\varepsilon)$ and the strain rate $(\dot{\varepsilon})$ data for the impacted specimens:

$$
\begin{aligned}
& \varepsilon=-2\left(\frac{C_{B}}{L_{s}}\right) \int_{0}^{t} \varepsilon_{R} d t \\
& \dot{\varepsilon}=-2\left(\frac{C_{B}}{L_{s}}\right) \varepsilon_{R} \\
& \sigma=\left(\frac{A_{B}}{A_{s}}\right) E_{B} \varepsilon_{T}
\end{aligned}
$$

Where $C_{B}$ is the elastic wave speed in the bar material and $L_{S}$ is the length of the test specimen. $A_{S}$ and $A_{B}$ are the cross-section areas of the specimens and the bars respectively. $\mathrm{E}_{\mathrm{B}}$ is the Young modulus of the bar material while $\left(\varepsilon_{T}\right)$ and $\left(\varepsilon_{R}\right)$ are the transmitted and reflected strain pulses respectively.

The digital image correlation (DIC) used in capturing the strain data in-situ during impact loading involved the use of two synchronized ultrahigh speed Photron FastCam SA5 cameras 
which produced images that depicted strain evolution along the test specimens during impact loading. One camera is arranged approximately at an angle of $45^{\circ}$ and the other at $-45^{\circ}$ to the horizontal, focussing on the specimens that lie along the horizontal (Fig. 2). The cameras themselves are capable of capturing images at up to 1,000,000 frames per second (fps). At the maximum frame rate, the cameras have a maximum horizontal resolution of 64 pixels and 16 pixels in the vertical direction at a $1 / 2,712,000$ second shutter speed. A frame rate of 124,000 fps was used for the actual testing. A number of trigger modes are made available through the Photron software for activating the cameras to capture images of the specimens as they deform under the high strain-rate compressive loading. Post processing of the image data using ARAMIS (i.e. the DIC commercial software from Trillion Quality Inc.) generated the strains in the deformed specimens.

Sample preparation for microscopic investigations involved an initial rough grinding using 500 and 800 grit emery papers. This was followed by polishing using $9 \mu \mathrm{m}$ MD Largo, $3 \mu \mathrm{m} \mathrm{MD} \mathrm{Mol}$ and $1 \mu \mathrm{m}$ MD Nap cloth, with their respective solutions in that order. The specimens were etched using a solution consisting of $25 \mathrm{ml}$ methanol, $25 \mathrm{ml} \mathrm{HCl}, 5 \mathrm{ml} \mathrm{HNO}{ }_{3}$ and 1 drop of HF. Etching time ranged between 30 and 40 seconds depending on the severity of the impact load.

\section{Results and Discussions}

\subsection{Microstructures of the as-received alloy}

Results of the microstructural investigation of the as-received alloy using the optical (OM) microscope and scanning electron microscope (SEM) are presented in Figs. 3 and 4 . The microstructure consists of dispersed second phase particles within a continuous $\alpha$-aluminum phase. Based on the sizes, two types of second phase particles can be identified in the micrographs (Fig. 3): coarse and fine particles. The coarse particles are irregular in shape and their dimension varies between 10 and $30 \mu \mathrm{m}$. The size of the fine particles is less than $1 \mu \mathrm{m}$ and they are also irregular in shape. The fine precipitates that are easily distinguishable from the continuous phase under an optical microscope are not so distinct in the SEM micrographs. This is due to the poor contrast between the continuous phase and the fine particles when 
imaged with secondary electrons. Some of the fine particles are indicated with white arrows in the SEM micrographs (Fig.4).

The second phase particles are intermetallic compounds that formed as a result of reactions of aluminum with the alloying element or impurities during solidification of aluminum alloys. The investigated AA 2219-T8 alloy is an aluminum-copper alloy containing up to $0.3 \mathrm{wt}$. \% Fe and 0.2-0.4 wt.\% Mn. During solidification of aluminum copper alloys, aluminum reacts with copper to form $\mathrm{Al}_{2} \mathrm{Cu}$, which are observed as the second phase particles in as-cast alloys. Homogenization treatment of as-cast Al-Cu alloys at high temperatures can lead to dissolution of $\mathrm{Al}_{2} \mathrm{Cu}$ particles. Impurity iron in $\mathrm{Al}-\mathrm{Cu}$ alloy reacts with aluminum and copper to form complex intermetallic compounds such as tetragonal $\mathrm{Al}_{7} \mathrm{Cu}_{2} \mathrm{Fe}$, or orthorhombic $\alpha(\mathrm{Al}, \mathrm{Cu}, \mathrm{Fe})$ particles during solidification, while the presence of $\mathrm{Mn}$ can also result in the formation of $\mathrm{Al}_{20} \mathrm{Cu}_{2} \mathrm{Mn}_{3}$ particles [22]. A number of previous investigations using X-ray diffraction (XRD) and energy dispersive X-ray spectroscopy (EDX) affirmed that the second phase particles in AA 2219 aluminum alloy to comprise mainly of undissolved $\mathrm{Al}_{2} \mathrm{Cu}$ and insoluble $\mathrm{Al}_{7} \mathrm{Cu}_{2} \mathrm{Fe}$ particles [23][25]. Therefore the two types of second phase particles identified in the microstructure are suggested to be $\mathrm{Al}_{2} \mathrm{Cu}$ and $\mathrm{Al}_{7} \mathrm{Cu}_{2} \mathrm{Fe}$. These are products of chemical reaction of aluminum with $\mathrm{Cu}$ or with $\mathrm{Cu}$ and Fe in liquid state prior to ingot casting. The EDX analysis of the coarse second phase particles in AA 2219 aluminum alloy indicated them to be $\mathrm{Al}_{2} \mathrm{Cu}$ intermetallic phase [16], [26]. The fine particles are therefore expected to be the insoluble $\mathrm{Al}_{7} \mathrm{Cu}_{2} \mathrm{Fe}$ intermetallic compound.

\subsection{Dynamic impact response}

The impact stress-strain curves for both the 4- $\mathrm{mm}$ and 5- $\mathrm{mm}$ long specimens are presented in Fig. 5. The curves indicate an initial elastic deformation up to a yield point, beyond which stress level first drops and then increases gradually with further increase in strain. The yield stresses for the 4-mm long specimens are slightly higher than those of the 5-mm long specimens especially at strain rates below $3000 \mathrm{~s}^{-1}$. A clear yield point with noticeable drop in flow stress beyond the yield point is only observed for specimens deformed at strain rates of $2000 \mathrm{~s}^{-1}$ and higher. The stress-strain curves of the specimens deformed at $1000 \mathrm{~s}^{-1}$ show no clear yield point 
but indicate drop in the rate of stress increase with strain once the deformation passed the elastic deformation region. The drop in stress beyond the yield point for specimens that deformed at higher strain rates is an indication of flow softening in the specimens, which may be attributed to the initial effects of temperature increase such as cross-slip, dislocation climb and dislocation annihilation. About $90 \%$ of impact energy is generally considered to convert to thermal energy which raises the temperature of a target subjected to dynamic impact loading. After the initial flow softening beyond the peak after yielding, stress starts to increase with further increase in strain. This is attributed to strain hardening, which is a consequent of dislocation multiplication during further plastic deformation resulting in dislocation interactions that hinder their motion. Frank and Read [27] first proposed the theory of dislocation multiplication during plastic deformation, which accounts for strain hardening when a metallic material is plastically deformed. The rate of strain hardening decreased with increasing strain due to increase in thermal softening as more heat was generated in the specimens. Eventually the flow stress plateaued at a maximum flow stress and the stress dropped rapidly due to thermomechanical instabilities caused by intense thermal softening of the specimens at higher strains. For both the 4-mm and 5-mm long test specimens, the maximum (peak) stresses were observed to increase slightly from about $650 \mathrm{MPa}$ to about $700 \mathrm{MPa}$ as the strain rate was raised from $1000 \mathrm{~s}^{-1}$ to $1500 \mathrm{~s}^{-1}$. As the strain rate was increased beyond $1500 \mathrm{~s}^{-1}$, no significant increase in peak stress was observed due to an early domineering effect of thermal softening at high strain rates.

The dynamic stress-strain curves obtained for the 5- $\mathrm{mm}$ and 4-mm long specimens at strain rates of 1000,1500 and $3000 \mathrm{~s}^{-1}$ are compared in Fig. 6 . The peak stresses of the 4-mm long specimens are slightly higher than those for 5-mm long specimens. This differences are small and appear to be within the limit of experimental error. However, this marginally higher peak stresses were observed for the $4 \mathrm{~mm}$-long specimens when compressed at strain-rate values of up to $2500 \mathrm{~s}^{-1}$. The peak stresses of the two specimens became relatively the same at higher strain rates. These results suggest that the effect of the difference in aspect ratio of the test specimens on the peak stress is marginal and this effect decreases with increasing strain rates. However the total true strains are considerably higher for the 5-mm long specimens than the 
4-mm long specimens (Figs. $5 \& 6$ ). The difference in the behaviour of the specimens may not be unconnected with the effects of aspect ratio on the average stress triaxiality in metallic alloys during mechanical loading. The results of an investigations by Bao and Wierzbicki [28] on the effects of aspect ratio on plastic deformation of AA 2024-T351 aluminum alloy indicated that the average stress triaxiality changed from -0.273 to -0.236 as the aspect ratio of the initial specimen was increased from 0.5 to 1.0. Contrary to what we observed under dynamic impact loading of AA 2219-T8 alloy in the current study, the equivalent strain to failure of the AA 2024T351 alloy was also reported to decrease with the increase in aspect ratio from 0.5 to 1.0. Molecular dynamic simulation of the high strain-rate behaviour of FCC copper crystals using embedded atom potential also suggested a dependence of plastic deformation, void nucleation and growth on stress triaxiality [29].

The relatively high peak flow stress (650 - $700 \mathrm{MPa}$ ) of the alloy under impact loading can be traced to its $\mathrm{T} 8$ tempered condition in addition to the solid solution strengthening effects of $\mathrm{Cu}$ atoms. The as-received alloy was solution heat treated, cold-worked and then artificially aged to obtain fine coherent precipitates. Such fine coherent precipitates are usually surrounded by large strain fields which are highly effective barriers to motion of dislocation resulting in high deformation resistance. Yielding in FCC aluminum alloy occurs when dislocation starts to move on application of load. The easier the motion of dislocation the lower the yield strength. Coherent precipitates are very effective in blocking the motion of dislocations because dislocation will rather cut through coherent precipitates than loop around it as stress is applied. A higher stress is required for dislocation cutting through a coherent precipitates than required to loop around incoherent second phase particles[30]. The high strength and hardness of peakaged AA 2219 alloy has been attributed to a mixture of coherent $\theta^{\prime \prime}$ and semi-coherent $\theta^{\prime}$ precipitates [25]. The T8 temper designation of the investigated AA 2219 alloy indicates that the alloy was cold worked after solution heat treatment and prior to age hardening. It has been suggested that dislocations offer potential sites for nucleation of fine precipitates during age hardening [31], [32]. Therefore, an increased precipitation of the strengthening precipitates can be expected in the T8 alloy leading to higher strength. 


\subsection{Microstructure evolution during dynamic impact loading.}

Heterogeneous deformation culminating in the formation of adiabatic shear bands was confirmed in the microstructures of the impacted AA 2219-T8 alloy. Both deformed and transformed shear bands were observed (Fig. 7). The deformed shear bands in this alloy are characterised by alignment of second phase particles in shear flow direction, implying considerable amount of plastic flow along these bands (Fig. 7a). This is an indication of significant amount of thermal softening occurring due to adiabatic heating in the region during deformation. It should be noted however that a perfect adiabatic condition is not achievable since some level of heat exchange between the shear band and the surrounding region will always occur. However, the amount of heat exchange during the very short deformation time $(<500 \mu \mathrm{s})$ is insignificant in view of the intense shear flow in the shear band region compared to the surrounding material. The microstructure of the transformed bands is somewhat different from that of the bulk material with the concentration of second phase particles being much lower in the transformed band compared to the bulk material (Fig. 7b).

The type of shear bands that develop in an alloy at high strain rates depends on the intensity of strain localization. It has been suggested that deformed bands first form and change to transformed bands as the intensity of strain localization reaches a critical value [12]. This can be corroborated in Fig. 7c in which a deformed shear band is observed ahead of a transformed band. From the optical micrograph shown in Fig. 7b, the coarse second phase particles appear to have dissolved inside the transformed bands during impact. Typical SEM micrographs of the impacted specimens are presented in Fig. 8. These micrographs also suggest dissolution of the coarse second phase particles inside the transformed bands. The remaining undissolved coarse second phase particles became elongated along the path of the transformed band. Cracks that initiated and propagated inside the transformed bands led to fragmentation of some specimens at high strain rates. The cracks were observed to initiate preferentially at the tip of the elongated second phase particles in the transformed bands. Dissolution of second phase particles has also been reported inside transformed bands formed in other aluminum alloys under dynamic impact loading [2], [9]. 
The intense strain and high temperature that developed inside the shear bands during impact accounts for the dissolution of the coarse second phase particles. An analysis by Chen et al. [33] showed that temperature increase in excess of $1500{ }^{\circ} \mathrm{C}$ can occur in the transformed bands in weldox $460 \mathrm{E}$ steel. Melting was reported to occur inside the transformed shear bands that formed in AISI 4340 and 1340 steels under dynamic impact loading, underscoring the intensity of adiabatic heating that led to the formation of transformed bands in these alloys [34], [35]. Xu et al. [9] suggested that the dissolution of second phase particles in transformed bands in AA 8090 aluminum alloy is an indication that the temperature reached inside the transformed bands during dynamic impact loading exceeded the solvus temperature, which is over $500{ }^{\circ} \mathrm{C}$ at standard atmospheric pressure. In the current study, only the coarse second phase particles dissolved inside the transformed bands while the fine ones remained insoluble. Previous investigations have shown that the second phase particles in AA 2219 aluminum alloy comprise mainly of undissolved $\mathrm{Al}_{2} \mathrm{Cu}$ and insoluble $\mathrm{Al}_{7} \mathrm{Cu}_{2} \mathrm{Fe}$ particles [23]-[25]. These suggest that the coarse second phase particles in the investigated alloy are the soluble $\mathrm{Al}_{2} \mathrm{Cu}$ while the fine particles that survive the intense adiabatic heating inside the transformed bands are the insoluble $\mathrm{Al}_{7} \mathrm{Cu}_{2} \mathrm{Fe}$ intermetallic compound.

The strain rates at which transformed shear bands were first observed in the 4-mm and 5-mm long specimens are $5500 \mathrm{~s}^{-1}$ and $3000 \mathrm{~s}^{-1}$ respectively. This is an indication of a dependency of the formation of adiabatic shear bands on the aspect ratio of the cylindrical test specimens. The specimen with the higher aspect ratio of 1.0 therefore exhibits a higher tendency to develop transformed bands than the specimen with a lower aspect ratio of 0.8 . The shorter specimens exhibited a more stable deformation. This again might not be unconnected with the difference in the stress states caused by variation in the length to diameter ratio of the test specimens as discussed earlier. Geometry was also reported to influence shear strain localisation in hat-shape specimens of iron and this effect was traced to the difference in the stress states [36]. 


\subsection{Digitial Image Correlation System Results}

The strain distribution on the surface of a 4-mm long specimens as it was deformed at $1000 \mathrm{~s}^{-1}$ at $8 \mu \mathrm{s}, 88 \mu \mathrm{s}, 176 \mu \mathrm{s}$, and $240 \mu \mathrm{s}$ after the start of deformation are presented in Fig. 9. Regions of strain localization, indicated by color other than blue, can be observed in the images. Whereas strain is nearly zero (blue) at the beginning of the experiment, high strain regions developed and grew within the specimen with increasing compression time. A plot of strain distribution along a horizontal section line drawn in the middle of the specimen is presented in Fig. 10. Like the strain distribution images, the plot was created by taking a horizontal line section in the middle of the shear localization stages obtained via ARAMIS. The strain distribution plot is another useful strain data that gives information about the potential shear strain localization sites along the specimens' length. The section establishes a series of data collection points along the sample's horizontal length relative to the visual images that were previously processed. Like the individual strain localization images, each individual curve on the resulting graph represents the strain data along the section line at different times during high strain-rate compression loading.

In Fig. 10, the beginning of the compression is represented by the lowest curve at $8 \mu$ s and the end with the highest curve obtained at $240 \mu$ s from the start of deformation. The intermediate curves represent time stages occuring at a linearly increasing time interval from $8 \mu$ s to $240 \mu \mathrm{s}$. At the beginning of compression, strain levels were close to zero but as time progresses, two distinct areas of non-uniform strain can be observed. These areas (specified by red circles) may indicate potential sites for strain localization leading to the formation of adiabatic shear bands. The characteristic features of the DIC maps and plots for the 5-mm long specimens are similar to the those for the 4-mm long specimens which are not reproduced in this paper.

\section{Conclusion}

Plastic deformation of cylindrical specimens of AA 2219-T8 aluminum alloy with length to diameter ratios of 0.8 and 1.0 were investigated at high strain rates in compression. The length to diameter ratio of the test specimens did not have significant influence on the flow stress 
under dynamic impact loading. However the total amount of deformation for a given strain rate is higher for the specimens with the higher aspect ratio. For deformation at $1500 \mathrm{~s}^{-1}$ as an example, the true strain were determined to be 0.4 and 0.6 for test specimens having length to diameter ratio of 0.8 and 1.0 respectively. Both deformed bands and transformed bands developed in the specimens depending on the strain rates. Deformed bands first developed once the strain rate reached $2500 \mathrm{~s}^{-1}$. Whereas the minimum strain rate required for formation of transformed band in the 4-mm long specimens is $5500 \mathrm{~s}^{-1}$, transformed bands was observed in the 5-mm long specimens when the strain rate was increased to $3000 \mathrm{~s}^{-1}$. This indicates that increasing the aspect ratio of the test specimen from 0.8 to 1.0 raised its susceptibility to formation of transformed bands. The concentration of second phase particles in the shear bands observed in the impacted specimens decreased with strain rates. Fracture of the investigated AA 2219-T8 aluminum alloy at high strain rates was initiated by cracking at the edge of elongated second phase particles inside the transformed bands.

\section{Acknowledgment}

The authors would like to acknowledge the financial support from the Department of Defense through the research and educational program HBCU/MSI (contract \# W911NF-12-1-061) under the direct supervision of Dr. Asher A. Rubinstein (Program Manager, ARO Solid Mechanics Program).

\section{References}

[1] S. D. Antolovich and R. W. Armstrong, "Plastic strain localization in metals: origins and consequences," Prog. Mater. Sci., vol. 59, no. March 2013, pp. 1-160, Jan. 2014.

[2] A. G. Odeshi, A. O. Adesola, and A. Y. Badmos, "Failure of AA 6061 and 2099 aluminum alloys under dynamic shock loading," Eng. Fail. Anal., vol. 35, pp. 302-314, Dec. 2013.

[3] R. W. Armstrong and F. J. Zerilli, "Dislocation mechanics aspects of plastic instability and shear banding," Mech. Mater., vol. 17, pp. 319-327, 1994.

[4] Y. Xu, J. Zhang, Y. Bai, and M. A. Meyers, "Shear Localization in dynamic deformation: microstructual evolution," Metall. Mater. Trans. A, vol. 39, no. 4, pp. 811-843, Feb. 2008.

[5] U. Andrade, M. A. Meyers, K. S. Vecchio, and A. . Chokshi, "Dynamic recrystallization in highstrain, high-strain-rate plastic deformation of copper," Acta Metall. Mater., no. 42, pp. 31833195, 1994. 
[6] M. A. Meyers, V. F. Nesterenko, J. C. LaSalvia, and Q. Xue, "Shear localization in dynamic deformation of materials: Microstructural evolution and self-organization," Mater. Sci. Eng. A, vol. 317, no. 1-2, pp. 204-225, 2001.

[7] S. Osovski, D. Rittel, P. Landau, and A. Venkert, "Microstructural effects on adiabatic shear band formation," Scr. Mater., vol. 66, no. 1, pp. 9-12, Jan. 2012.

[8] S. Osovski, D. Rittel, and A. Venkert, "The respective influence of microstructural and thermal softening on adiabatic shear localization," Mech. Mater., vol. 56, pp. 11-22, Jan. 2013.

[9] Y. B. Xu, W. L. Zhong, Y. J. Chen, L. T. Shen, Q. Liu, Y. L. Bai, and M. A. Meyers, "Shear localization and recrystallization in dynamic deformation of 8090 Al-Li alloy," Mater. Sci. Eng. A, vol. 299, no. 1-2, pp. 287-295, Feb. 2001.

[10] Z. G. Gao, X. M. Zhang, Y. S. Zhao, M. an Chen, and H. J. Li, "The effect of strain rate on the microstructure of 2519 A aluminium alloy plate impacted at $573 \mathrm{~K}$," J. Alloys Compd., vol. 481, pp. 422-426, 2009.

[11] A. Ghosh, A. Adesola, J. A. Szpunar, A. G. Odeshi, and N. P. Gurao, "Effect of tempering conditions on dynamic deformation behaviour of an aluminium-lithium alloy," Mater. Des., vol. 81, pp. 110, Sep. 2015.

[12] A. O. Adesola, A. G. Odeshi, and U. D. Lanke, "The effects of aging treatment and strain rates on damage evolution in AA 6061 aluminum alloy in compression," Mater. Des., vol. 45, pp. 212-221, Mar. 2013.

[13] G. M. Owolabi, A. G. Odeshi, M. N. K. Singh, and M. N. Bassim, "Dynamic shear band formation in Aluminum 6061-T6 and Aluminum 6061-T6/Al203 composites," Mater. Sci. Eng. A, vol. 457, no. 1-2, pp. 114-119, May 2007.

[14] S. J. Pérez-Bergquist, G. T. R. Gray, E. K. Cerreta, C. P. Trujillo, and A. Pérez-Bergquist, "The dynamic and quasi-static mechanical response of three aluminum armor alloys: 5059, 5083 and 7039," Mater. Sci. Eng. A, vol. 528, no. 29-30, pp. 8733-8741, 2011.

[15] C. V. A. Narasayya, P. Rambabu, M. K. Mohan, R. Mitra, and N. E. Prasad, "Tensile Deformation and Fracture Behaviour of an Aerospace Aluminium Alloy AA2219 in Different Ageing Conditions," Procedia Mater. Sci., vol. 6, pp. 322-330, 2014.

[16] K. Surekha, B. S. Murty, and K. P. Rao, "Microstructural characterization and corrosion behavior of multipass friction stir processed AA2219 aluminium alloy," Surf. Coatings Technol., vol. 202, no. 17, pp. 4057-4068, May 2008.

[17] K. Surekha, B. S. Murty, and K. Prasad Rao, "Comparison of corrosion behaviour of friction stir processed and laser melted AA 2219 aluminium alloy," Mater. Des., vol. 32, no. 8-9, pp. 45024508, 2011.

[18] K. Surekha, B. S. Murty, and K. Prasad Rao, "Effect of processing parameters on the corrosion behaviour of friction stir processed AA 2219 aluminum alloy," Solid State Sci., vol. 11, no. 4, pp. 907-917, 2009.

[19] S. Suenger, M. Kreissle, M. Kahnert, and M. F. Zaeh, "Influence of Process Temperature on Hardness of Friction Stir Welded High Strength Aluminum Alloys for Aerospace Applications," Procedia CIRP, vol. 24, no. Mic, pp. 120-124, 2014. 
[20] A. K. Jha, S. V. S. N. Murty, K. Sreekumar, and P. P. Sinha, "High strain rate deformation and cracking of AA 2219 aluminium alloy welded propellant tank," Eng. Fail. Anal., vol. 16, no. 7, pp. 2209-2216, 2009.

[21] R. K. Gupta and S. V. S. N. Murty, "Analysis of crack in aluminium alloy AA2219 weldment," Eng. Fail. Anal., vol. 13, no. 8, pp. 1370-1375, Dec. 2006.

[22] M. Warmuzek, "Metallographic Techniques for Aluminum and its Alloys," in ASM Handbook Vol 9: Metallography and Microstructures, 2004, pp. 711-751.

[23] S. Roy, B. R. Nataraj, S. Suwas, S. Kumar, and K. Chattopadhyay, "Microstructure and texture evolution during accumulative roll bonding of aluminium alloys AA2219/AA5086 composite laminates," J. Mater. Sci., vol. 47, no. 17, pp. 6402-6419, 2012.

[24] V. M. J. Sharma, K. S. Kumar, B. N. Rao, and S. D. Pathak, "Effect of microstructure and strength on the fracture behavior of AA2219 alloy," Mater. Sci. Eng. A, vol. 502, no. 1-2, pp. 45-53, Feb. 2009.

[25] E. M. Elgallad, Z. Zhang, and X.-G. Chen, "Effect of two-step aging on the mechanical properties of AA2219 DC cast alloy," Mater. Sci. Eng. A, vol. 625, pp. 213-220, Feb. 2015.

[26] G. V. Narayana, V. M. J. Sharma, V. Diwakar, K. S. Kumar, and R. C. Prasad, "Fracture behaviour of aluminium alloy 2219-T87 welded plates," Sci. Technol. Weld. Join., vol. 9, no. 2, pp. 121-130, 2004.

[27] F. C. Frank and W. T. Read, "Multiplication processes for slow moving dislocations," Phys. Rev., vol. 79, no. 4, pp. 722-723, 1950.

[28] Y. Bao and T. Wierzbicki, "A Comparative Study on Various Ductile Crack Formation Criteria," J. Eng. Mater. Technol., vol. 126, no. 3, p. 314, 2004.

[29] E. T. Seppälä, J. Belak, and R. E. Rudd, "Effect of stress triaxiality on void growth in dynamic fracture of metals: A molecular dynamics study," Phys. Rev. B - Condens. Matter Mater. Phys., vol. 69, no. 13, 2004.

[30] R. W. Hertzberg, R. P. Vinci, and Hertzberg. J.L., Deformation and Fracture Mechanics of Engineering Materials, Fifth. Wiley, 2012.

[31] D. Bakavos, P. B. Prangnell, B. Bes, and F. Eberl, "The effect of silver on microstructural evolution in two 2xxx series Al-alloys with a high $\mathrm{Cu}: \mathrm{Mg}$ ratio during ageing to a T8 temper," Mater. Sci. Eng. A, vol. 491, no. 1-2, pp. 214-223, Sep. 2008.

[32] M. Kumar, S. Singh, and D. B. Goel, "Electron microscopic studies of thermomechanically aged 2218 aluminium alloy," Bull. Mater. Sci., vol. 10, no. 3, pp. 217-222, May 1988.

[33] X. W. Chen, Q. M. Li, and S. C. Fan, "Initiation of adiabatic shear failure in a clamped circular plate struck by a blunt projectile," Int. J. Impact Eng., vol. 31, no. 7, pp. 877-893, Aug. 2005.

[34] A. G. Odeshi, S. Al-ameeri, S. Mirfakhraei, F. Yazdani, and M. N. Bassim, "Deformation and failure mechanism in AISI 4340 steel under ballistic impact," Theor. Appl. Fract. Mech., vol. 45, no. 1, pp. 18-24, Feb. 2006.

[35] H. M. Ghomi and A. G. Odeshi, "The effects of microstructure, strain rates and geometry on dynamic impact response of a carbon-manganese steel," Mater. Sci. Eng. A, vol. 532, pp. 308315, Jan. 2012. 
[36] E. K. Cerreta, J. F. Bingert, G. T. Gray, C. P. Trujillo, M. F. Lopez, C. A. Bronkhorst, and B. L. Hansen, "Microstructural examination of quasi-static and dynamic shear in high-purity iron," Int. J. Plast., vol. 40, pp. 23-38, Jan. 2013. 


\section{Figure(s)}

\section{FIGURES}
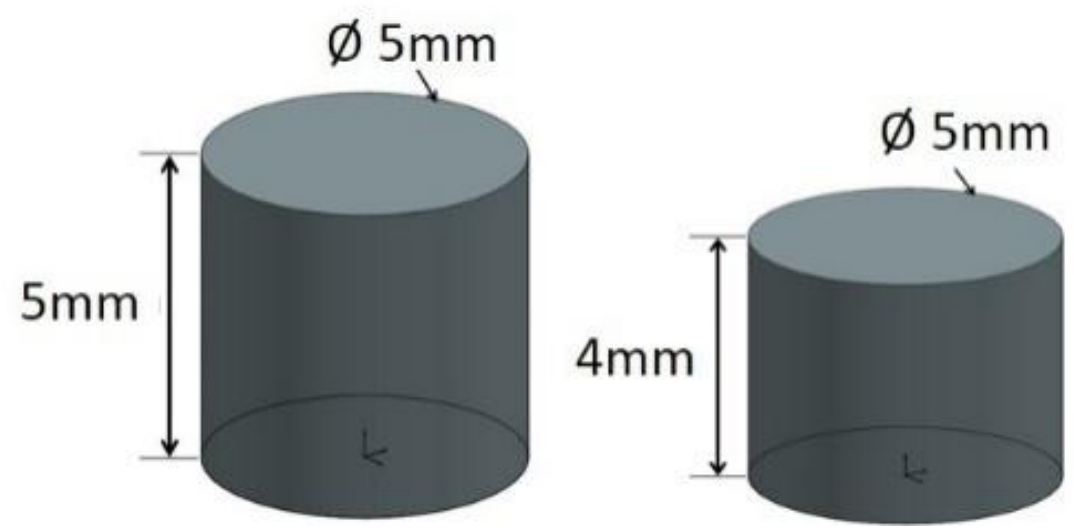

Fig. 1: Geometry of the test specimens 


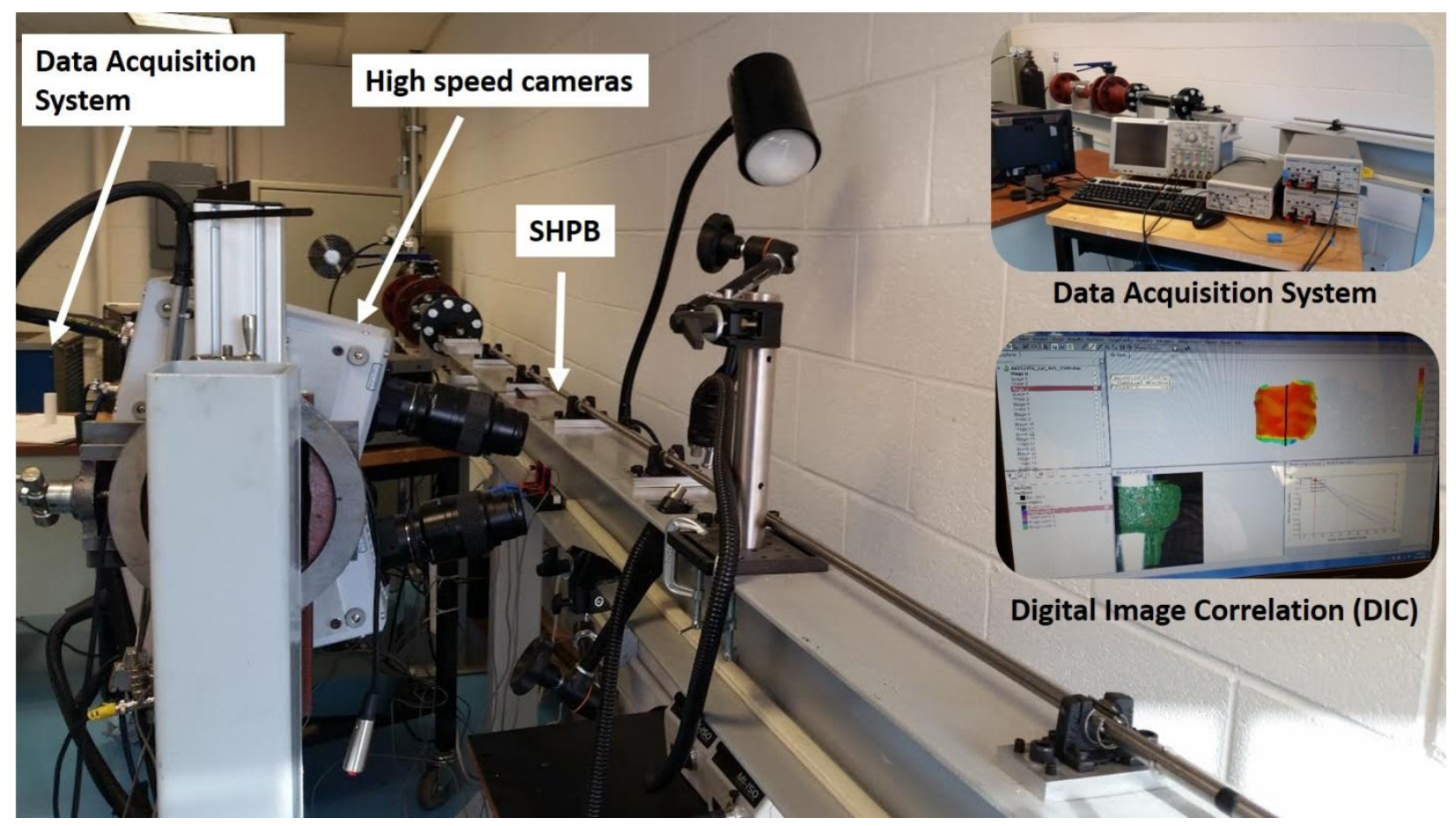

Fig. 2: Photographs of the split Hopkinson pressure bar synchronized with data acquisition and digital image correlation systems. 


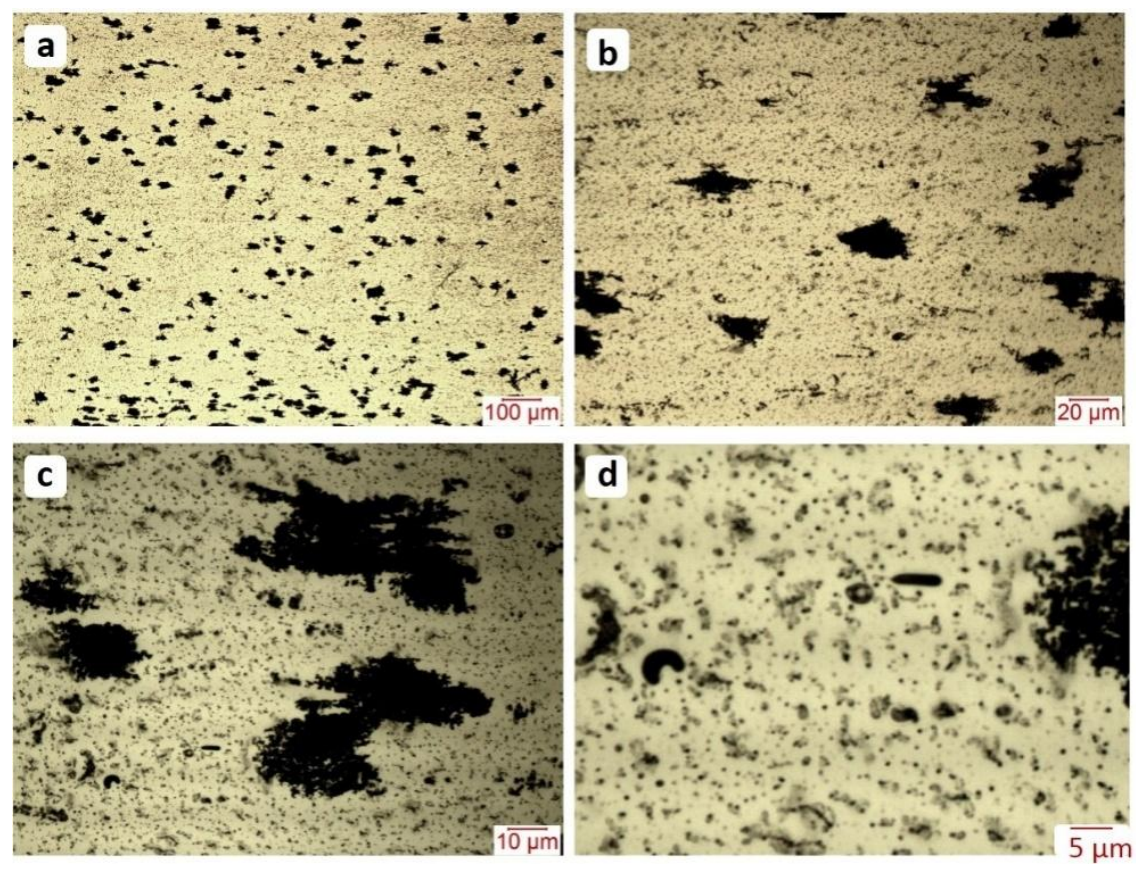

Fig. 3: Optical micrographs, at different magnifications, of the as received AA2219-T8 aluminum alloy showing morphology and distribution of second phase particles. 

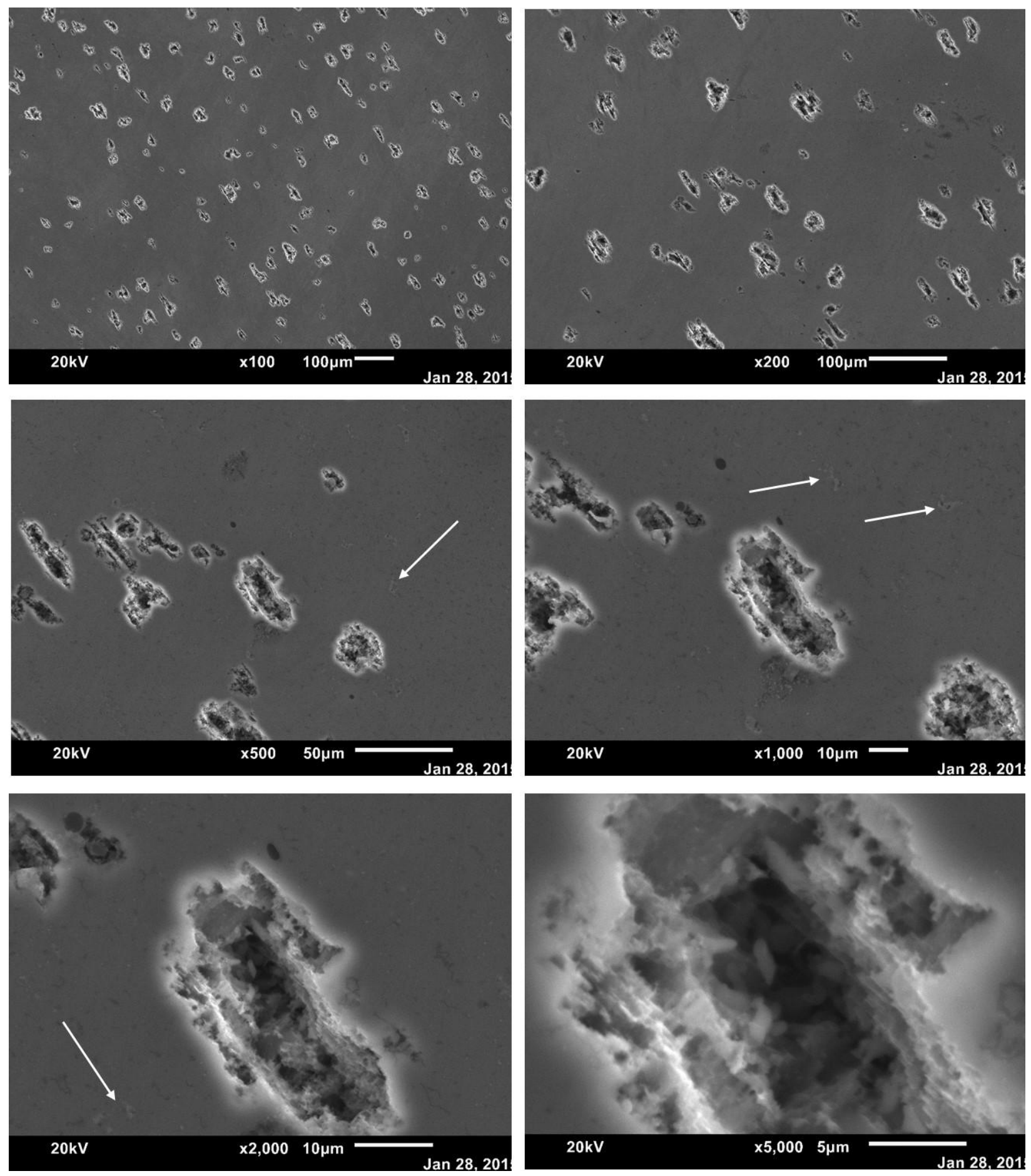

Fig. 4: SEM micrographs of as-received AA2219-T8 aluminum alloy indicating elongated second phase particles at different magnifications. Arrows point to the fine second phase particles observed in the optical micrographs. 


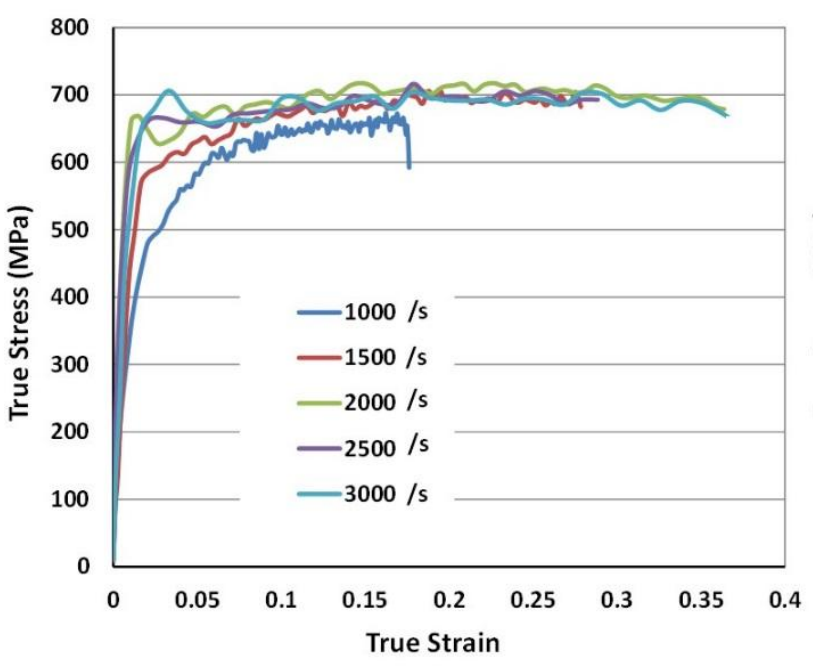

(a)

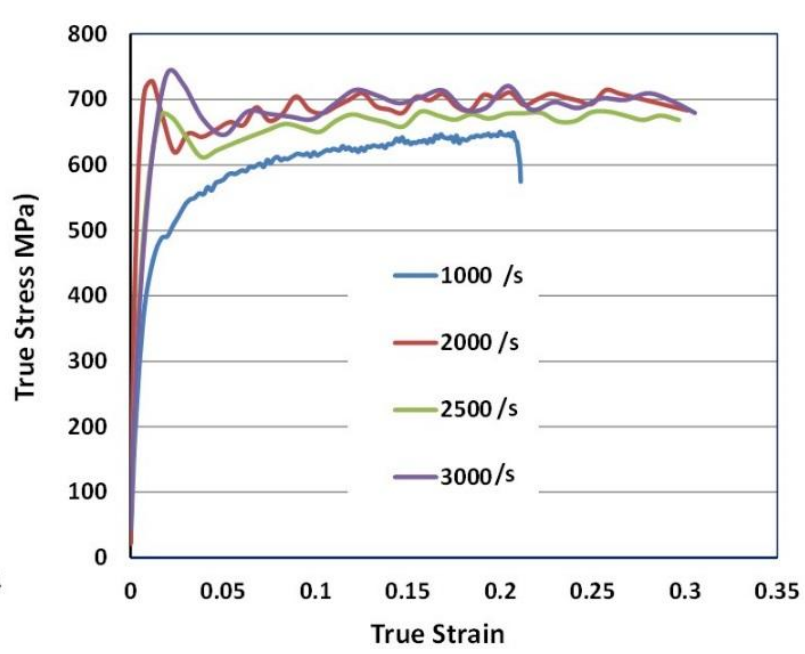

(b)

Fig. 5: Dynamic stress-strain curves for (a) 4mm-long and (b) 5-mm long specimens under impact loading. 


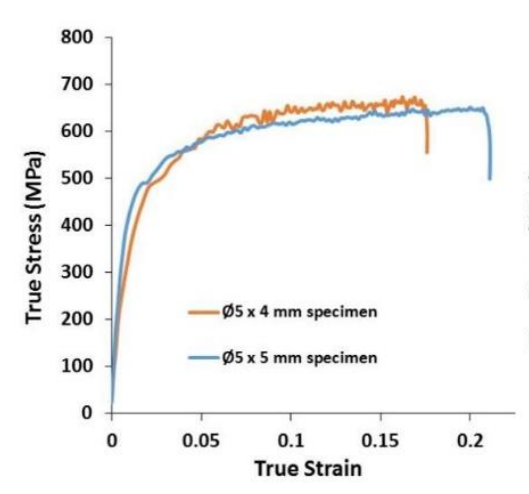

(a)

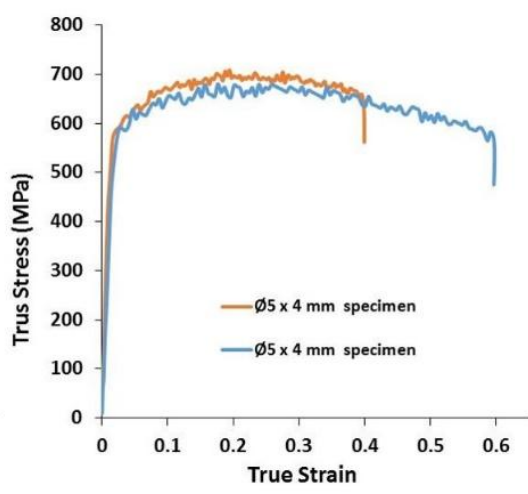

(b)

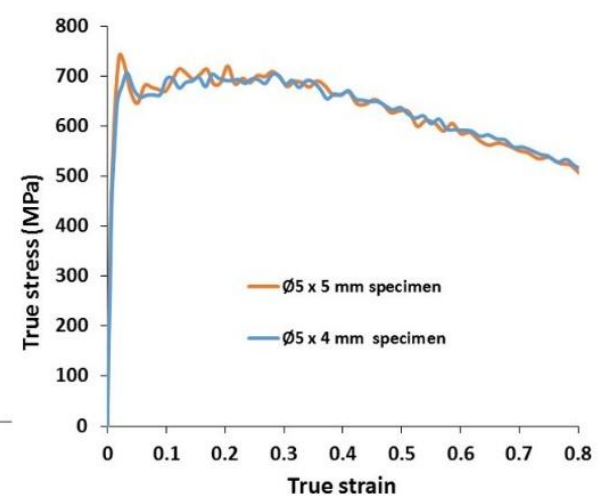

(c)

Fig. 6: Comparison of stress-strain curves for 4-m and 5-mm long cylindrical specimens compressed at (a) $1000 \mathrm{~s}^{-1}$ and (b) $1500 \mathrm{~s}^{-1}$ and (c) $3000 \mathrm{~s}^{-1}$ 

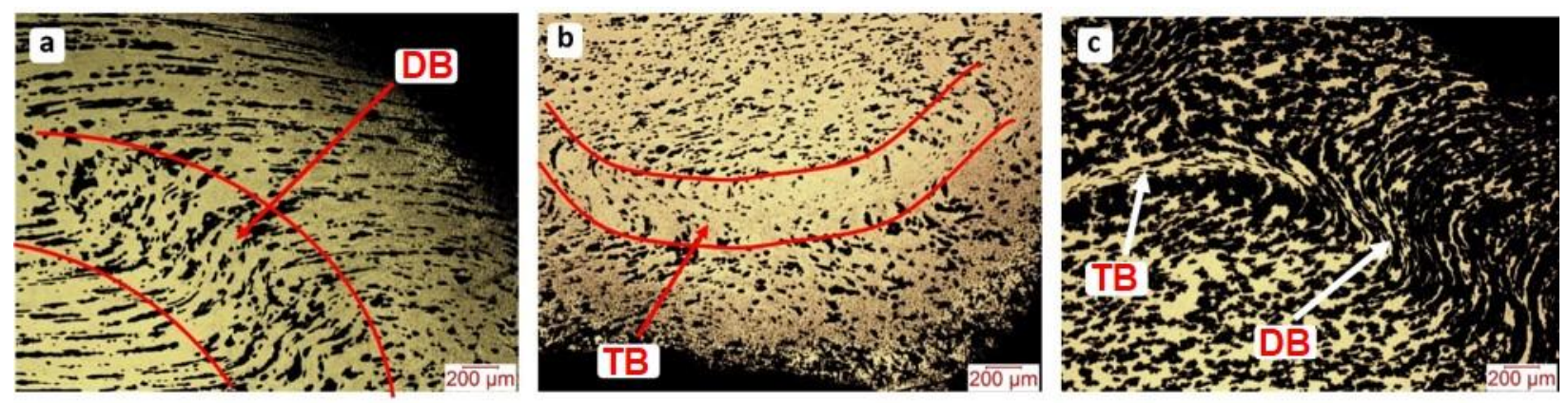

Fig. 7: Optical micrographs showing (a) deformed band (DB) (b) transformed band (TB) and (c) both DB and TB in an impacted specimen. 

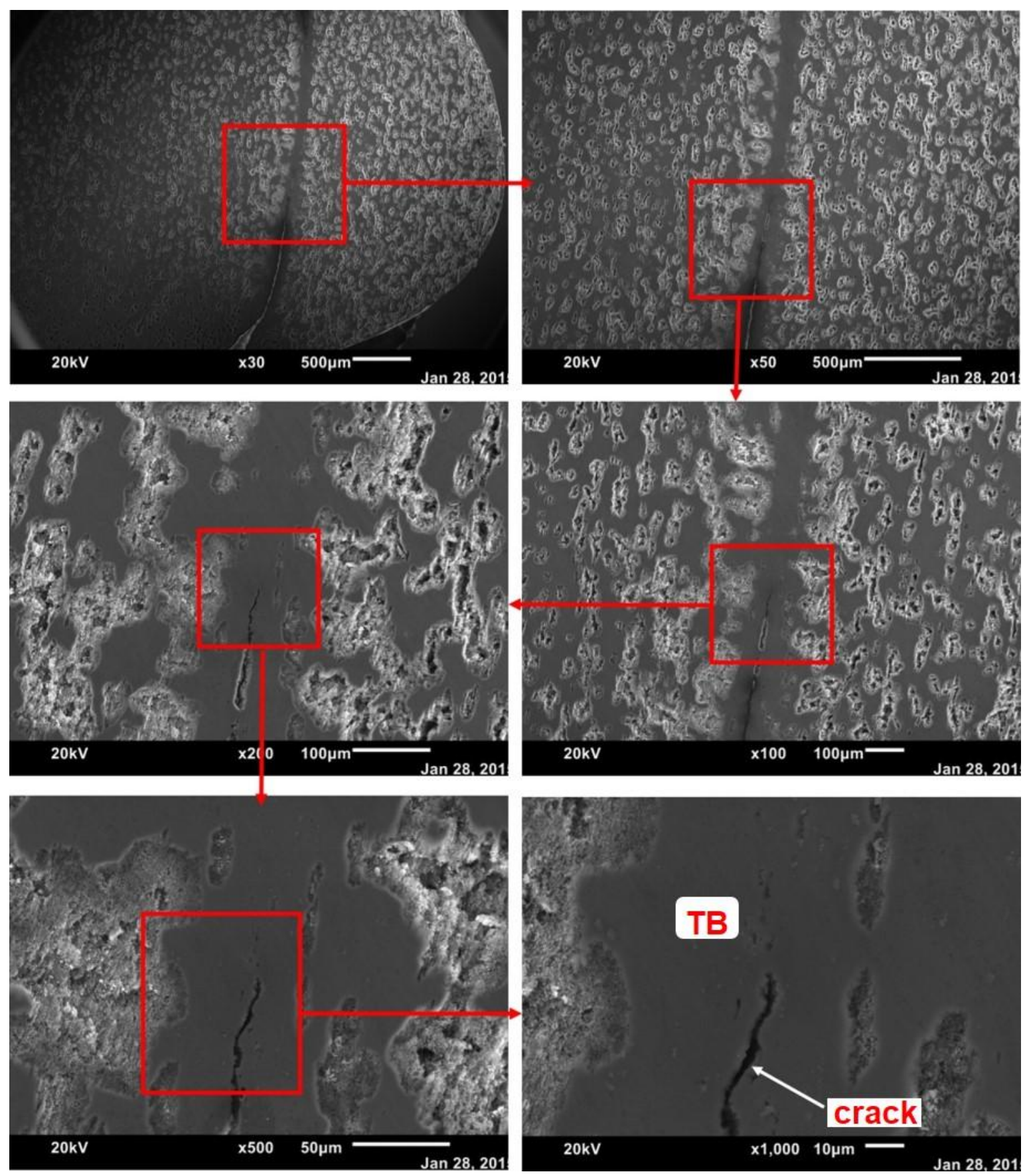

Fig. 8: SEM Micrographs, at different magnifications, showing transformed bands in an impacted cylindrical specimen. 

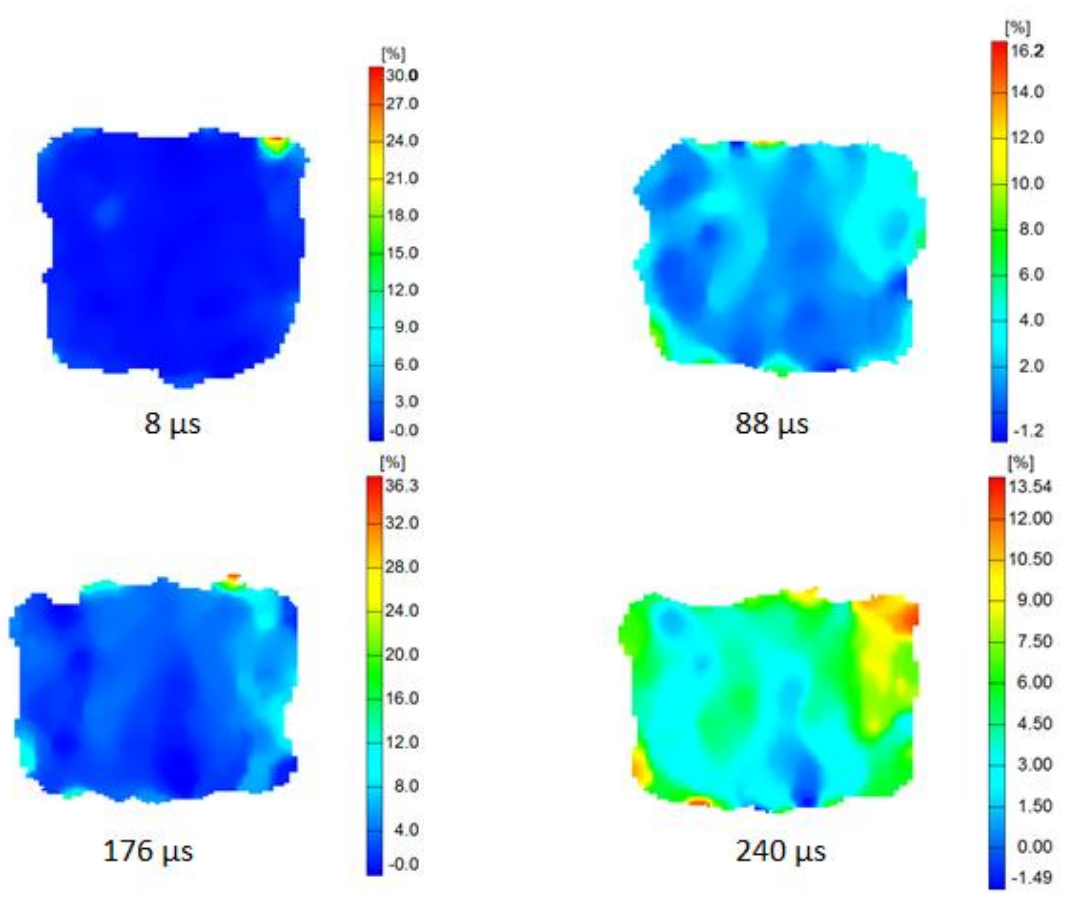

Fig. 9: Strain distribution along the length of the 4-mm long cylinderical specimen deformed at $1000 \mathrm{~s}^{-1}$ 


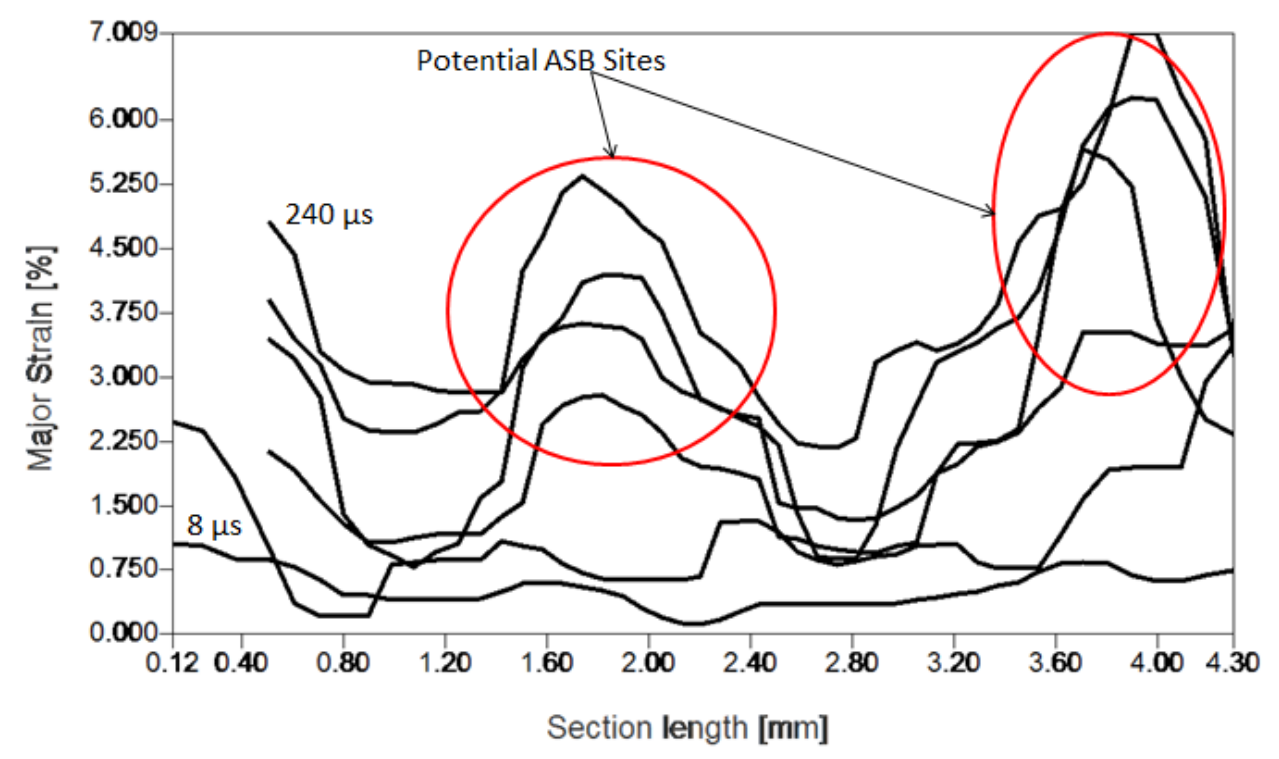

Fig. 10: Progression of strain distribution over time along the length of a specimen as it deformed at $1000 \mathrm{~s}^{-1}$ 
LIST OF TABLES

Table 1: Nominal composition of the investigated AA 2219 aluminum alloy

\begin{tabular}{|ccccccccccc|}
\hline Component & $\mathrm{Al}$ & $\mathrm{Cu}$ & $\mathrm{Fe}$ & $\mathrm{Mg}$ & $\mathrm{Mn}$ & $\mathrm{Si}$ & $\mathrm{Ti}$ & $\mathrm{V}$ & $\mathrm{Zn}$ & $\mathrm{Zr}$ \\
\hline \multirow{2}{*}{ Wt. \% } & $91.5-$ & $5.8-$ & $\leq 0.3$ & $\leq 0.02$ & $0.2-$ & $\leq 0.2$ & $0.02-$ & $0.05-$ & $\leq 0.1$ & $0.1-$ \\
& 93.8 & 6.8 & & & 0.4 & & 0.1 & 0.15 & & 0.25 \\
\hline
\end{tabular}

